\section{Natural products for treating or preventing influenza}

\author{
Catherine E. Ulbricht, Dawn Costa \\ Natural Standard Research Collaboration \\ One Davis Square, Somerville, MA, USA
}

\section{Abstract}

Natural products - including botanicals, minerals, and other substances produced by organisms - not only hold historical significance in various medical traditions, but they also form the basis of many modern-day drugs. On one hand, natural products are considered to be a form of complementary and alternative medicine (CAM); as with many CAM therapies, natural products are often used for primary disease prevention and treatment - or as adjuncts to conventional therapies - despite uncertain effectiveness or safety. On the other hand, natural products have given rise to numerous conventional drugs, which are widely used in mainstream medicine and compose the primary therapeutic strategies for numerous conditions (including influenza). In this review, the available evidence on the use of select natural products for the treatment or prevention of influenza is discussed. Finally, a brief overview of an established influenza drug with botanical origins is provided.

\section{Select natural products used for influenza treatment and prevention}

Conventional treatments for influenza include antivirals, antipyretics, and agents that provide temporary symptomatic relief. Similarly, natural influenza therapies are used for purported antiviral, antipyretic, and symptom-relieving effects. The same therapies may also be used in the general population for various related and unrelated indications, such as cardiovascular disease risk reduction, common cold symptoms, or overall well-being. Select natural products that are commonly used in influenza treatment are summarized below. These therapies should not be used in place of vaccination or other FDA-approved therapies, and patients are advised to discuss all therapies used (conventional or alternative) with their primary healthcare providers.

\section{Andrographis (Andrographis spp.)}

Background and mechanism of action

The leaves of plants from the genus
Andrographis have had a long history of use in Indian folk medicine and Ayurveda to treat a variety of ailments (including influenza). ${ }^{1}$ The Chinese and Thai herbal medicine systems have also incorporated this herb, renowned in these traditions mostly for its "bitter" properties as a treatment for digestive problems and for a variety of febrile illnesses. More recently, this herb, in its standardized extract form, has become popular in Scandinavia as a remedy for upper respiratory infections (URI) and influenza. One commonly used preparation is the standardized andrographis extract Kalm Cold $^{\circledR}$, which has been shown to have low toxicity in vitro and in vivo. ${ }^{2}$ Clinical trials using the standardized product Kan Jang ${ }^{\circledR}$ (Swedish Herbal Institute) have shown reasonably strong evidence that andrographis may be effective in reducing symptom severity and duration in upper respiratory tract infections (URIs), both in children and adults, if started within 36-48 hours of the onset of symptoms; ${ }^{3}$ however, fewer studies have examined andrographis specifically for influenza.

Andrographolide, a diterpene lactone compound, is believed to be the principal active agent. ${ }^{4}$ Other purported active constituents include trimethoxy flavone (TMF), a naturally occurring flavone that is isolated from Andrographis viscosula and used in the treatment of dyspepsia, influenza, malaria, and respiratory functions and as an astringent and antidote for poisonous stings of some insects. Andrographolide inhibits NF- $\kappa \mathrm{B}$ binding to DNA in vitro, reducing expression of a variety of inflammatory proteins, including COX-2. ${ }^{5}$ In rat neutrophils, it also appears to exert antiinflammatory action via a decrease in gene expression required for neutrophil adhesion and transmigration. ${ }^{6}$ Andrographolide alone and the standardized andrographis combination product Kan Jang ${ }^{\circledast}$ were found to increase the formation of TNF- $\alpha$ and $\beta 2 \mathrm{MG}$ in vitro; the fixed combination was more effective than andrographolide alone. ${ }^{7}$ Andrographis has been shown to inhibit the secretion of proinflammatory cytokines by influenza A virus (H1N1)-infected human epithelial cells in vitro. ${ }^{8}$

There is reasonably strong evidence from clinical trials to suggest that andrographis is effective in reducing the severity and the duration of URIs when treatment is started within the first 36-48 hours of symptoms. Based on animal and in vitro studies, it appears that andrographis may have a number of other potential therapeutic uses, including as an anti-inflammatory agent and as a treatment for chemically induced hepatotoxicity. It has also been studied in human clinical trials for influenza and familial Mediterranean fever; it may be moderately effective in reducing symptoms in both of these conditions, although further research is merited in these areas.
Correspondence: Catherine E. Ulbricht, Natural Standard Research Collaboration, One Davis Square, Somerville, MA 02144, USA.

E-mail: ulbricht@naturalstandard.com

Key words: influenza, complementary and alternative medicine, integrative medicine, natural products.

Received for publication: 13 September 2010.

Revision received: 9 December 2010.

Accepted for publication: 9 December 2010.

This work is licensed under a Creative Commons Attribution 3.0 License (by-nc 3.0).

(C) Copyright C.E. Ulbricht et al., 2011

Licensee PAGEPress, Italy

Alternative Medicine Studies 2011; 1:e2

doi:10.4081/ams.2011.e2

There are historical data to suggest that andrographis has been effective in the past as part of a regimen to treat influenza in Asian medical systems. The one clinical trial to date of a standardized andrographis preparation does report a significant reduction in the duration and severity of symptoms, as well as a decrease in time off from work, in patients treated for influenza with this herbal. More studies specifically looking at influenza, with clear diagnostic criteria for distinguishing flu from simple URIs, are needed to confirm this finding.

\section{Clinical evidence}

Kulichenko et al. carried out two randomized parallel-group trials of the SHA-10 extract of andrographis (Kan Jang ${ }^{\circledR}$, Swedish Herbal Institute) in adults diagnosed with influenza. Patients who had been ill for more than 36-48 hours at the time of presentation were excluded. In the pilot study, for which randomization procedures were not described in detail, 71 patients were treated with Kan Jang ${ }^{\circledR}$ (two tablets three times daily for 3-5 days) and 469 patients were treated with conventional therapy. In the second trial, which had a clearer randomization procedure, 35 patients were treated with Kan Jang ${ }^{\circledR}$ and 31 with conventional treatment. Outcomes assessed were symptoms by patient self-evaluation on days one and five of the study period, and clinical examination by a physician on days one and five. In the pilot study, investigators found that only $30 \%$ of treated subjects developed what they described as lingering or "complicated" influenza, while $68 \%$ of the control group developed this condition $(\mathrm{P}<0.01$ difference). In the second study, they found both that symptoms disappeared more rapidly in the treatment than in the control group (1-2.5 days sooner, depending on the particular symptom, $\mathrm{P}<0.01$ for all), and that the duration of sick leave in the treated group was significantly shorter than in the con- 
trol group (7.2 days vs. 9.8 days, $\mathrm{P}<0.01$ ). Although the study suffers from its poorly described randomization procedure and a lack of a standardized outcome measures for symptoms, it does seem to provide preliminary evidence that andrographis extract may be effective not only for standard URIs but also for influenza specifically.

\section{Echinacea (Echinacea spp.)}

\section{Background and mechanism of action}

Natural medicine experts frequently recommend oral extracts of echinacea for the treatment of the common cold, influenza, and other conditions requiring immune stimulation. Echinacea has been shown to alter the course of influenza infection in mice. ${ }^{10,11}$ Echinacea may have direct effects on the influenza virus ${ }^{12}$ such as interference with receptor binding and viral entry into cells ${ }^{1,13}$ or inhibition of viral growth. ${ }^{1,14}$ However, some studies suggest that the anti-influenza effects of echinacea may be through the modulation of cytokines and/or interferons, ${ }^{11,14-16}$ an effect that is retained by echinacea root tinctures for up to two years. ${ }^{15,17}$ Recent studies have shown echinacea alkamides to modulate pro-inflammatory cytokine cannabinoid type-2 (CB2) receptors, presenting a novel and potentially significant immunomodulatory mechanism for echinacea. ${ }^{18,19}$

Studies have examined the efficacy of echinacea in treating upper respiratory infections in general, but the overall evidence is conflicting and insufficient to either support or rule out potential benefits. ${ }^{20-22}$ Relatively little clinical research has focused specifically on influenza. Despite a paucity of clinical evidence, the German Commission $\mathrm{E}$ has approved the oral use of Echinacea purpurea for supportive treatment of influenza-like infections and lower urinary tract infections, and for topical treatment of poorly healing wounds/ chronic ulcerations. These indications are also noted in monographs published by the World Health Organization (WHO).

\section{Clinical evidence}

Lindenmuth and Lindenmuth conducted a randomized controlled trial of Echinacea Plus ${ }^{\circledast}$ tea (containing echinacea, lemongrass, and spearmint) vs. placebo for upper respiratory tract symptoms. ${ }^{23}$ The tea contained the equivalent of 1,275 mg of dried herb and root per tea bag. Participants were instructed to drink 5-6 cups of tea on the first day and titrate down by one cup daily for the next five days. The experimental group rated the effectiveness of echinacea tea as 4.1 on a 5-point scale (SD 0.96), while the control group rated their tea as 2.8 (SD 0.095), with a $\mathrm{P}<0.001$. There was also a statistically significant (although small) difference in the number of days symptoms last- ed and in the number of days before symptoms diminished in the treatment group vs. control. The statistical analysis may not have been appropriate (t-test for sum scores), but this methodological weakness would not likely explain the results. Therefore, echinacea tea, when taken at the first onset of symptoms, may be effective in relieving symptoms of the common cold and in abbreviating the course of the illness.

\section{Elder (Sambucus spp.)}

\section{Background and mechanism of action}

Sambucus is a genus containing several species of small trees or shrubs, and various parts of the plant (including the bark, leaves, flowers, or berries) have been used for the treatment of influenza. The berries of European elder are recognized by the German Commission E for various medicinal uses. ${ }^{24}$ The aerial parts of the elder plant contain lectins that have notable carbohydrate-binding properties $^{25}$ and are therefore often used to study influenza virus agglutination. The antiviral mechanisms of elder lectins are believed to involve rendering viruses nonfunctional by binding influenza virus hemagglutinin, its major viral surface protein that facilitates infection. Preclinical studies suggest that $S$. nigra (flowers and berry) may inhibit influenza virus types $\mathrm{A}$ and $\mathrm{B}$ by reducing hemagglutination of red blood cells and inhibiting viral replication. ${ }^{26,27}$ Elderberry flavonoids have also been shown to bind influenza virus and prevent infection in vitro. ${ }^{28}$

Sambucol $^{\circledR}$ is a popular influenza remedy that contains $38 \%$ standardized black elderberry extract (for adults) or 19\% standardized black elderberry juice (for children). ${ }^{27}$ Many different formulations of this product are available. Sambucol ${ }^{\circledast}$ Active Defense ${ }^{\mathrm{TM}}$ contains a $38 \%$ standardized black elderberry extract, plus vitamin C, zinc, propolis, and a proprietary blend of Echinacea angustifolia and Echinacea purpurea. The standardized elderberry product Sinupret $^{\circledast}$ (Quanterra ${ }^{\circledR}$ Sinus Defense) is an herbal mixture containing $18 \mathrm{mg}$ Flos Sambucus nigra (elder flower), $18 \mathrm{mg}$ Herba Verbenae off. (vervain wort), $6 \mathrm{mg}$ Radix Gentianae luteae (gentian root), $18 \mathrm{mg}$ Flos Primulae veris cum calycibus (cowslip flowers with calyx), and $18 \mathrm{mg}$ Herba Rumicis acetosae (sorrel). ${ }^{29}$ Sambucol $^{\circledR}$ has been shown to increase the production of both pro-inflammatory and anti-inflammatory cytokines. ${ }^{30,31}$

\section{Clinical evidence}

A case report exists of an HIV-positive woman, taking no HIV drugs, who experienced a viral load drop from 17,000 to 4,000 after ingestion of Sambucol $^{\circledR}$ with olive leaf extract. ${ }^{32}$ The report also included a placebocontrolled, double-blind study of Sambucol ${ }^{\circledR}$ associated with a rapid recovery from influen$\mathrm{za}$ and inhibited replications of nine other strains of the flu virus by elderberry.

Zakay-Rones et al. conducted a randomized, double-blind, placebo controlled study of Sambucol $^{\circledR}$ (a syrup containing elderberry juice, raspberry extract, glucose, citric acid, and honey) in the treatment of influenza in otherwise healthy individuals (children and adults) not previously vaccinated against the flu, located in an Israeli agricultural community. ${ }^{27}$ Patients were included who had at least three symptoms (fever, myalgia, nasal discharge, cough) of less than 24 hours' duration. Children received 2 tbsp. daily and adults received 4 tbsp. daily for three days. Age range and mean age were similar between groups. This was not an intent-to-treat analysis, and out of 40 subjects who were initially enrolled and randomized, 13 were disqualified prior to analysis, due to crossover or protocol violations (five in the treatment group and eight in the placebo group). In subjects who were analyzed, convalescent phase serologies demonstrated higher antibody titers to influenza B in the group treated with Sambucol ${ }^{\circledR}$, although these results were not statistically significant, and only demonstrated a trend in favor of the treatment group. Follow-up of symptoms was adequately recorded over six days, and significant improvement in symptoms was observed in $93.3 \%$ of treated patients within two days, versus the control group, in which it took six days to see improvement in $92.7 \%$ of patients $(\mathrm{P}<0.001)$. A complete cure was seen within 23 days in Sambucol ${ }^{\circledR}$-treated patients $(90 \%)$, whereas six days were needed in the placebo group. Although randomization and blinding were adequately described, this study was limited by the small sample size, lack of intent-totreat analysis, and use of influenza-B rather than influenza-A titer measurement.

Zakay-Rones et al. later conducted another randomized, double-blind, placebo-controlled study of oral elderberry syrup in the treatment of influenza A and B virus infections during the influenza season of 1999-2000 in Norway.3. Patients aged 18-54 years with influenza-like symptoms for 48 hours or less were enrolled. Patients were given $15 \mathrm{~mL}$ of elderberry or placebo syrup four times a day for five days and recorded their symptoms using a visual analogue scale. There was no intent-to-treat analysis. Symptoms were relieved on average four days earlier, and use of rescue medication was significantly less in those receiving elderberry extract compared with placebo. The authors concluded that elderberry extract seems to offer an efficient, safe, and cost-effective treatment for influenza. Although the study was randomized and blinded, this study was limited by the small sample size, lack of intent-totreat analysis, and failure to report any adverse effects or lack of compliance. 


\section{Ginseng (Panax spp.)}

Background and mechanism of action

Panax ginseng has been used in traditional Chinese medicine (TCM) for more than 2,000 years for a wide range of indications. Ginseng is believed to boost immune function and, thus, has been implicated for treatment of respiratory infectious disease. ${ }^{34}$ In humans and animals, ginseng has been shown to enhance cellular immune function by stimulating natural killer cell activity, ${ }^{35-39}$ macrophages ${ }^{40}$ tumor necrosis factor (TNF)- $\alpha$ production, ${ }^{41}$ cytokine production, ${ }^{42,43}$ antibody-dependent cellular cytotoxicity, ${ }^{38,44}$ intracellular killing in neutrophils, blastogenesis of circulating lymphocytes, ${ }^{45}$ and antibody production..$^{35}$ Ginseng has also been shown to potentiate the effect of vaccines $^{46}$ and display anticomplement activity. ${ }^{47}$ Preclinical studies have suggested that ginseng has mitogenic activity on lymphocytes, ${ }^{48}$ but preliminary clinical studies did not find significant effects on peripheral blood leukocytes or lymphocyte subsets. ${ }^{49}$ Immunomodulating effects of ginseng may be attributable to its constituents, such as root-derived panaxanes-polysaccharides,$^{50}$ ginsenosides that can differentially modulate lymphocyte proliferation, ${ }^{51}$ and ginsenan S-IIA, a potent inducer of IL-8 production by human monocytes and THP-1 cells. ${ }^{52}$ Certain multi-ingredient preparations, such as CKBM (Panax ginseng, Schisandra chinensis, Fructus crataegi, Ziziphus jujube, and Glycine max), have also been shown to regulate intracellular signaling and the production of cytokines. ${ }^{53}$ The immuno-regulatory functions of a sacchariderich proprietary American ginseng extract (Panax quinquefolius, CVT-E002) by CV Technologies Inc. may be due to stimulation of a panel of inflammatory cytokines secretion from monocytes and augmentation of IFN- $\gamma$ secretion upon influenza stimulation. Clinical research has found Cold-fX ${ }^{\circledast}$, containing CVTE002, to be effective in the prevention and treatment of upper respiratory infections. ${ }^{5456}$ Cold-f $\mathrm{X}^{\circledast}$ may increase NK cell and macrophage activity, leading to increased cytolytic and phagocytic killing of pathogens and IFN- $\gamma$ secretion. Evidence from in vitro and in vivo studies indicates that Cold-f $\mathrm{X}^{\circledast}$-induced antiviral effects could be related to its immunomodulating properties. ${ }^{34,57-61}$

Ginseng seems to stimulate T-cell and polymorphonuclear (PMN) leukocyte activity, increase clearance of bacterial infections treated with antibiotics, and improve immune response to and efficacy of influenza immunization. Numerous clinical studies have been or are being conducted with Cold-fX®, involving a total of more than 1,000 study subjects in diverse populations, including healthy adults, nursing home seniors, and athletes. These trials include: two open trials with professional sport teams for safety, tolerability, severity, duration of cold and flu-like symptoms, general performance, and immune system functions, ${ }^{62}$ one controlled trial with high-performance athletes for doping control urinalysis, ${ }^{63}$ and three double-blind, placebo-controlled trials in seniors for the prevention of colds and flu. ${ }^{55,64}$ A pivotal large-scale randomized, double-blind, placebo-controlled trial has recently been completed in healthy adults, examining the preventative effect of Cold-fX ${ }^{\circledR}$ for upper respiratory tract infections. ${ }^{54}$ Recently, a multicenter trial was launched to investigate the effectiveness of Cold- $\mathrm{f} \mathrm{X}^{\circledast}$ in the prevention of respiratory infections in community-dwelling seniors who had been vaccinated against influenza. Cold-fX ${ }^{\circledast}$ appeared safe, well tolerated, and potentially effective for preventing acute respiratory illness due to influenza and respiratory syncytial virus (RSV)..$^{55,64}$ These evaluations are based on a few studies, which were all presented by the same lead author. Critical examination of this indication by independent groups is needed for a more definite efficacy evaluation of ginseng for immunostimulation. Future research should also identify the conditions that may benefit most from such immunostimulant properties. Conclusions about safety and efficacy of Cold-f $\mathrm{X}^{\circledast}$ should not be considered equivalent to other ginseng preparations without further supportive evidence. Ginseng has been associated with an increased risk of bleeding, ${ }^{65}$ so it is contraindicated in acute inflammatory conditions (such as asthma), hypertension, and situations involving blood loss. ${ }^{66}$

\section{Clinical evidence}

Scaglione et al. found in a randomized, double-blind, placebo-controlled trial that Panax ginseng increases efficacy of influenza vaccination. ${ }^{67}$ Two hundred twenty-seven healthy volunteers from three private practices were randomly assigned to either ginseng (G115 ${ }^{\circledR}$, $200 \mathrm{mg}$ daily) or placebo for 12 weeks. Vaccination was administered after four weeks of treatment. Antibody titers, natural killer cell (NK) activity, intercurrent illnesses, and adverse events were assessed in 2-4-week intervals. Until the end of the study, NK activity almost doubled in the ginseng group, while it remained unchanged in the placebo group $(\mathrm{P}<0.0001)$. Antibody titers were one-third higher in the ginseng as compared to the placebo group. The number of common cold/ influenza episodes was two-thirds lower in the ginseng vs. the placebo group $(\mathrm{P}<0.001)$. Nine patients in the ginseng group complained about adverse events, mainly nausea or insomnia (one control patient complained about insomnia). The results of this well-conducted trial indicate that ginseng may be an effective adjuvant to vaccination against influenza.

McElhaney et al. conducted a randomized, double-blind, placebo-controlled trial in community-dwelling seniors to assess the effects of a proprietary extract of American ginseng root (Cold-fX ${ }^{\circledast}$ ) in the prevention of acute respiratory illness. ${ }^{64}$ Volunteers were included in this study if they were generally healthy and aged 65 and older. Those taking immunosuppressive drugs and corticosteroids and those with a history of allergy or known renal, pulmonary, or hepatic abnormalities were excluded. The participants were asked to take two capsules every morning of either Cold-fX ${ }^{\circledast}$ or placebo (200 mg per capsule) for a period of four months. After four weeks on the study drug, the patients received a standard dose of influenza vaccine. Patients self-reported the following symptoms: fever, sore throat, cough, nasal congestion, chills, headache, fatigue, or aches/pains. Patients also were asked to record if the study medication helped in reducing the duration of their symptoms. The effects of Cold-fX $\mathrm{X}^{\circledast}$ or placebo treatment on the frequency and duration of symptoms related to an acute respiratory illness (ARI) prior to the onset of influenza season were analyzed. The Pearson chi-square test was used to compare the proportions of subjects reporting symptoms related to ARI and adverse events. For the subset of subjects who reported ARI-related symptoms, the number of days for which symptoms were reported was calculated, and the two groups were compared using unpaired t-tests. Nausea, heartburn, or diarrhea were reported in six of 22 (27\%) of patients; side effects were not significantly different from the placebo group (four of 21, 19\%). Dry mouth was also reported in two of 22 patients (9\%), but again, this was not significantly different from the placebo group (zero of 21). ${ }^{64}$ Muscle and joint pain were reported in four of 22 (18\%) of patients, although side effects were not significantly different from placebo group (three of $21,14 \%)$. During the first eight weeks of the study, in subjects reporting ARI-related symptoms, the average duration of the symptoms per subject was not found to be statistically different between the groups. However, in the last eight weeks, the duration in the Cold-fX ${ }^{\circledast}$ group was found to be $55 \%$ shorter than in the placebo group (5.6 vs. 12.6 days, $\mathrm{P}=0.04$ ). The authors concluded that Cold-fX ${ }^{\circledR}$ supplementation during an early "cold and flu" season could potentially help in reducing the frequency and duration of symptoms related to ARI in community-dwelling adults aged 65 years or older and immunized against influenza. During the early part of the colds and flu season, regular modest dosing of Cold- $\mathrm{fX}^{\circledR}$ reduced the relative risk of ARI by $48 \%$ and was well tolerated by the study participants.

McElhaney et al. conducted two phase 2 randomized, double-blind, placebo-controlled, parallel arm investigations in 2000 and 2001 to assess the effects of a proprietary extract of 
American ginseng root (CVT-E002) in the prevention of acute respiratory illness..$^{55}$ Volunteers from assisted-living or nursing home facilities were included in this study if they were aged 60 or older. Those taking immunosuppressive drugs and corticosteroids and those with a history of allergy or active renal, pulmonary, or hepatic abnormalities were excluded. Eighty-nine (2000) and 109 (2000-2001) subjects enrolled, with an average age of 81 and 83.5 , respectively; $74 \%$ were women. Approximately $90 \%$ had received influenza vaccines in each of the two years. Subjects received oral administration of a proprietary ginseng extract, CVT-E002, $200 \mathrm{mg}$ or placebo twice daily for either eight or 12 weeks, depending on the study. Cold-f $\mathrm{X}^{\circledR}$ is standardized to contain $90 \%$ poly-furanosylsaccharides. Acute respiratory illness (ARI) was defined as two new respiratory symptoms or one with a constitutional symptom, which defined the primary outcome of this study. Secondary outcomes included confirmation of viral ARI by culture [influenza or respiratory syncytial virus (RSV)] or serology for influenza. Laboratory safety monitoring was done at zero, four, and eight, or 12 weeks. There were no significant differences in the demographic data between CVT-E002 and placebo groups in either of the studies. The number of side effects was similar between placebo and CVTE002 groups, with gastrointestinal, nervous, and cardiovascular effects occurring. Combined results in the two studies showed that $11 \%$ of the placebo group ( $8 \%$ of whom required hospitalization) and $6 \%$ of the CVTE002 group (4\% of whom required hospitalization) experienced a serious adverse effect during the study. All of the serious adverse effects were judged to be unrelated to the study medication. There was no significant difference noted in the primary outcome for the number of ARIs defined by symptoms alone. And there was no significant difference in the severity or duration of symptoms related to ARI between the two groups in either study. For the secondary endpoints, pooled data corrected for drug exposure time showed that the incidence of laboratory-confirmed influenza illness (LCII) was greater in placebo- (seven cases out of 101 subjects) than CVT-E002-treated (one out of 97) groups (odds ratio (OR)=7.73, $\mathrm{P}=0.033$ ). Combined data for LCII and RSV illness were also greater in placebo- (nine out of 101) than CVT-E002-treated (one out of 97) groups $(\mathrm{OR}=10.50, \mathrm{P}=0.009)$, for an overall $89 \%$ relative risk reduction of ARI in the CVT-E002 group. Although a potentially promising study, the randomization methods and double-blinding methods were unclear in this study. This study did include power calculations for adequate study size and pooled data from two influenza seasons. Based on this study, CVTE002 does not appear to reduce symptoms of influenza, but may affect laboratory-confirmed ARI.

McElhaney et al. conducted a preliminary study on the safety, tolerability, and efficacy of Cold-fX ${ }^{\circledast}$ treatment for flu-like or cold symptoms, which was presented at the First International Scientific Congress on Nutrition \& Athletic Performance, Edmonton, Alberta, August $8-11,2001 .^{62}$ Studies of Cold-fX ${ }^{\circledR}$ were conducted during the 1997-98 and 1998-99 seasons with the Edmonton Oilers Hockey Club. The first study included subjects on daily or intermittent treatment starting at the first onset of symptoms. In the intermittent treatment group, $71 \%$ (five of seven) reported that Cold-f $\mathrm{X}^{\circledast}$ prevented the cold from developing and that it made them feel better. In the daily treatment group, $57 \%$ (eight of 14) reported they felt less run down while traveling, and $50 \%$ (seven of 14 ) reported that Cold- $\mathrm{fX}^{\circledR}$ allowed them to recover faster from a cold. At season end, $83 \%$ (10 of 12) believed that taking Cold-f $\mathrm{X}^{\circledR}$ helped them to stay healthy during the season, and $67 \%$ (eight of 12) reported that if they got a cold, their recovery time was faster. A second study was undertaken, with subjects receiving daily treatment with Cold$\mathrm{fX}^{\circledast}$, or no Cold-fX $\mathrm{f}^{\circledast}$ in the control group. Peripheral blood lymphocytes were challenged with influenza virus, and supernatants and cell lysates assayed. Early-season control group results indicated that IL-10 decreased 34.4\%, and TNF- $\alpha$ decreased 44.4\%, whereas Granzyme B increased 82.5\%. End-of-season results differed: TNF $\alpha$ increased $21.8 \%$, and IL10 and Granzyme B did not change. By comparison, Cold-fX ${ }^{\circledast}$-treated subjects had altered immune responses manifested by stabilizing cytokine or effector levels. These studies suggested that Cold-f $\mathrm{X}^{\circledR}$ treatment may prevent the onset or reduce the severity of symptoms related to colds and flu and could do so by maintaining the production of inflammatory and immunologic mediators at consistent levels. There was no blinding, randomization, or placebo in these studies, only outcomes.

\section{Tamiflu: an established influenza drug with natural origins}

Natural products are often regarded as alternative therapies with little or no scientific basis; however, it is important to remember that a significant proportion of the current pharmaceutical market - indeed, even the most commonly used drugs - are derived from naturally occurring plant compounds. In the last decade alone, more than 20 newly approved drugs were derived from natural sources, including plants and microorganisms. ${ }^{68}$ It has been estimated that $50 \%$ of contemporary drugs (those used in the last few decades) are either directly extracted from plants or chemically derived from naturally occurring compounds. ${ }^{69}$ Notable examples include the opiates, which are derived from the latex sap of the opium poppy (Papaver somniferum) and compose one of the best-selling classes of prescription medications. ${ }^{70}$ Another example is aspirin (acetylsalicylic acid), the world's first-ever synthetic drug; this commonly used analgesic and anti-inflammatory is derived from salicylic acid, a constituent found in willow (Salix spp.) and meadowsweet (Filipendula ulmaria, formerly Spirea ulmaria). Aspirin has been called "the most popular painkiller in the world" and has shown efficacy in the prevention of colon cancer. ${ }^{71}$

Oseltamivir (Tamiflu ${ }^{\circledR}$ ) is a preeminent example of a conventional drug that is derived from a naturally occurring compound. Oseltamivir inhibits neuraminidase, an influenza enzyme that facilitates viral release from infected cells, thus blocking the virus from spreading in an infected host. ${ }^{72}$ Tamiflu $^{\circledR}$ can inhibit both influenza A and B, and is used to prevent and treat influenza in adults and children. ${ }^{73-77}$ The Chinese star anise (Illicium verum), which has a long history of culinary and medicinal use in China, is the primary industrial source of shikimic acid, the key precursor to oseltamivir (Tamiflu). Limited supplies of star anise and low yields of shikimic acid are limiting factors in oseltamivir production. Additional sources of shikimic acid include sweetgum fruit (Liquidambar spp.) and ginkgo (Ginkgo biloba); however, Illicium species contain the highest concentrations. $^{78}$

\section{Conclusions}

Overall, there is insufficient evidence to support the efficacy of many natural products in the treatment of influenza or influenza-like illnesses. Likewise, risk-benefit analyses remain unclear for most natural products. Nonetheless, studies have uncovered antiviral and immunomodulatory mechanisms of action for several phytochemicals, suggesting that they have potential benefits in upper respiratory infections (including influenza). Further studies are needed to determine clinical efficacy, define mechanisms of action, and delineate the safety parameters for natural influenza remedies. Phytochemicals may also form the basis of novel drugs for influenza and influenza-like conditions.

\section{References}

1. Gokara M, Sudhamalla B, Amooru DG, 
Subramanyam R. Molecular interaction studies of trimethoxy flavone with human serum albumin. PLoS One 2010;5:e8834.

2. Chandrasekaran CV, Thiyagarajan P, Sundarajan K, et al. Evaluation of the genotoxic potential and acute oral toxicity of standardized extract of Andrographis paniculata (KalmCold). Food Chem Toxicol 2009;47: 1892-902.

3. Kligler B, Ulbricht C, Basch E, et al. Andrographis paniculata for the treatment of upper respiratory infection: a systematic review by the natural standard research collaboration. Explore (NY) 2006;2:25-9.

4. Jada SR, Hamzah AS, Lajis $\mathrm{NH}$, et al. Semisynthesis and cytotoxic activities of andrographolide analogues. J Enzyme Inhib Med Chem 2006;21:145-55.

5. Hidalgo MA, Romero A, Figueroa J, et al. Andrographolide interferes with binding of nuclear factor-kappaB to DNA in HL-60derived neutrophilic cells. Br J Pharmacol 2005; 144:680-6.

6. Shen YC, Chen CF, Chiou WF. Andrographolide prevents oxygen radical production by human neutrophils: possible mechanism(s) involved in its anti-inflammatory effect. Br J Pharmacol 2002;135:399-406.

7. Panossian A, Davtyan T, Gukassyan N, et al. Effect of andrographolide and Kan Jang fixed combination of extract SHA-10 and extract SHE-3 - on proliferation of human lymphocytes, production of cytokines and immune activation markers in the whole blood cells culture. Phytomedicine 2002; 9:598-605.

8. Ko HC, Wei BL, Chiou WF. The effect of medicinal plants used in Chinese folk medicine on RANTES secretion by virus-infected human epithelial cells. J Ethnopharmacol 2006;107:205-10.

9. Kulichenko LL, Kireyeva LV, Malyshkina EN, Wikman G. A randomized, controlled study of Kan Jang versus amantadine in the treatment of influenza in Volgograd. $\mathrm{J}$ Herb Pharmacother 2003;3:77-93.

10. Bodinet C, Mentel R, Wegner U, et al. Effect of oral application of an immunomodulating plant extract on Influenza virus type A infection in mice. Planta Med 2002;68:896-900.

11. Fusco D, Liu X, Savage C, et al. Echinacea purpurea aerial extract alters course of influenza infection in mice. Vaccine 2010; 28:3956-62.

12. Wacker A, Hilbig W. [Virus-inhibition by echinacea purpurea (author's transl)]. Planta Med 1978;33:89-102.

13. Pleschka S, Stein M, Schoop R, Hudson JB. Anti-viral properties and mode of action of standardized Echinacea purpurea extract against highly pathogenic avian influenza virus (H5N1, H7N7) and swine-origin H1N1 (S-OIV). Virol J 2009;6:197.

14. Sharma M, Anderson SA, Schoop R, Hudson JB. Induction of multiple pro-inflammatory cytokines by respiratory viruses and reversal by standardized Echinacea, a potent antiviral herbal extract. Antiviral Res 2009;83:165-70.

15. Senchina DS, McCann DA, Flinn GN, et al. Echinacea tennesseensis ethanol tinctures harbor cytokine- and proliferation-enhancing capacities. Cytokine 2009;46:267-72.

16. Cech NB, Kandhi V, Davis JM, et al. Echinacea and its alkylamides: effects on the influenza A-induced secretion of cytokines, chemokines, and PGE from RAW 264.7 macrophage-like cells. Int Immunopharmacol 2010;10:1268-78.

17. McCann DA, Solco A, Liu Y, et al. Cytokineand interferon-modulating properties of Echinacea spp. root tinctures stored at -20 degrees $\mathrm{C}$ for 2 years. J Interferon Cytokine Res 2007;27:425-36.

18. Raduner S, Majewska A, Chen JZ, et al. Alkylamides from Echinacea are a new class of cannabinomimetics. Cannabinoid type 2 receptor-dependent and -independent immunomodulatory effects. J Biol Chem 2006;281:14192-206.

19. Gertsch J, Schoop R, Kuenzle U, Suter A. Echinacea alkylamides modulate TNF-alpha gene expression via cannabinoid receptor CB2 and multiple signal transduction pathways. FEBS Lett 2004;577:563-9.

20. Gillespie EL, Coleman CI. The effect of Echinacea on upper respiratory infection symptom severity and quality of life. Conn Med 2006;70:93-7.

21. Arroll B. Non-antibiotic treatments for upperrespiratory tract infections (common cold). Respir Med 2005;99:1477-84.

22. Ernst E. The risk-benefit profile of commonly used herbal therapies: Ginkgo, St. John's Wort, Ginseng, Echinacea, Saw Palmetto, and Kava. Ann Intern Med 2002;136:42-53.

23. Lindenmuth GF, Lindenmuth EB. The efficacy of echinacea compound herbal tea preparation on the severity and duration of upper respiratory and flu symptoms: a randomized, double-blind placebo-controlled study. J Altern Complement Med 2000; 6:327-34.

24. Vlachojannis JE, Cameron M, Chrubasik S. A systematic review on the sambuci fructus effect and efficacy profiles. Phytother Res 2010;24:1-8.

25. Shibuya N, Goldstein IJ, Broekaert WF, et al. The elderberry (Sambucus nigra L.) bark lectin recognizes the Neu5Ac(alpha 26)Ga/GalNAc sequence. J Biol Chem 1987; 262:1596-601.

26. Serkedjieva J, Manolova N, ZgorniakNowosielska I, et al. Antiviral activity of the infusion (SHS-174) from flowers of Sambucus nigra L., aerial parts of Hypericum perforatum L., and roots of Saponaria officinalis L. against influenza and herpes simplex viruses. Phytotherapy Research 1990;4:97100.

27. Zakay-Rones Z, Varsano N, Zlotnik M, et al.
Inhibition of several strains of influenza virus in vitro and reduction of symptoms by an elderberry extract (Sambucus nigra L.) during an outbreak of influenza B Panama. J Altern Complement Med 1995;1:361-9.

28. Roschek B, Jr, Fink RC, McMichael MD, et al. Elderberry flavonoids bind to and prevent H1N1 infection in vitro. Phytochemistry 2009;70:1255-61.

29. Neubauer N, März RW. Placebo-controlled, randomized double-blind clinical trial with Sinupret ${ }^{\circledR}$ sugar coated tablets on the basis of a therapy with antibiotics and decongestant nasal drops in acute sinusitis. Phytomedicine 1994;1:177-81.

30. Barak V, Birkenfeld S, Halperin T, Kalickman I. The effect of herbal remedies on the production of human inflammatory and anti-inflammatory cytokines. Isr Med Assoc J 2002;4:91922.

31. Barak V, Halperin T, Kalickman I. The effect of Sambucol, a black elderberry-based, natural product, on the production of human cytokines: I. Inflammatory cytokines. Eur Cytokine Netw 2001;12:290-6.

32. Konlee M. A new triple combination therapy. Posit Health News 1998;(No 17):12-4.

33. Zakay-Rones Z, Thom E, Wollan T, Wadstein J. Randomized study of the efficacy and safety of oral elderberry extract in the treatment of influenza A and B virus infections. J Int Med Res 2004;32:132-40.

34. Jing Y, et al. A proprietary extract of Panax quinquefolius (CVT-E002) stimulates inflammatory cytokine secretion from monocytes and augments IFN-gamma secretion from NK cells in response to influenza virus stimulation. Internal Report.

35. Jie YH, Cammisuli S, Baggiolini $M$ Immunomodulatory effects of Panax Ginseng C.A. Meyer in the mouse. Agents Actions 1984;15:386-91.

36. Kim JY, Germolec DR, Luster MI. Panax ginseng as a potential immunomodulator: studies in mice. Immunopharmacol Immunotoxicol 1990;12:257-76.

37. Ro JY, Kim KH. The adjuvant activity of a single purified ginsenosids ( $\mathrm{Rb}, \mathrm{Rg}$ ) from Korean Red Ginseng Radix. The Journal of Allergy and Clinical Immunology 1999;103: S210-S211.

38. See DM, Broumand N, Sahl L, Tilles JG. In vitro effects of echinacea and ginseng on natural killer and antibody-dependent cell cytotoxicity in healthy subjects and chronic fatigue syndrome or acquired immunodeficiency syndrome patients. Immunopharmacology 1997;35:229-35.

39. Yun TK, Choi SY. Preventive effect of ginseng intake against various human cancers: a case-control study on 1987 pairs. Cancer Epidemiol Biomarkers Prev 1995;4:401-8.

40. Scaglione F, Cogo R, Cocuzza C, et al. Immunomodulatory effects of Panax ginseng 
C.A.Meyer (G115) on alveolar macrophages from patients suffering with chronic bronchitis. Int J Immunother 1994; 10:21-4.

41. Zhou DL, Kitts DD. Peripheral blood mononuclear cell production of TNF-alpha in response to North American ginseng stimulation. Can J Physiol Pharmacol 2002;80: 1030-3.

42. Nakaya TA, Kita M, Kuriyama H, et al. Panax ginseng induces production of proinflammatory cytokines via toll-like receptor. J Interferon Cytokine Res 2004;24:93-100.

43. Spelman K, Burns J, Nichols D, et al. Modulation of cytokine expression by traditional medicines: a review of herbal immunomodulators. Altern Med Rev 2006; 11:128-50.

44. Scaglione F, Ferrara F, Dugnani S, et al. Immunomodulatory effects of two extracts of Panax ginseng C.A. Meyer. Drugs Exp Clin Res 1990;16:537-42.

45. Liu J, Wang S, Liu H, et al. Stimulatory effect of saponin from Panax ginseng on immune function of lymphocytes in the elderly. Mech Ageing Dev 1995;83:43-53.

46. Daggfeldt A, Rivera E, Hu S. Ginseng improve the antibody response to porcine parvovirus and Erysipelothrix rhusiopatiae. Scand J Immunol 1999;50:326.

47. Tomoda M, Hirabayashi K, Shimizu N, et al. Characterization of two novel polysaccharides having immunological activities from the root of Panax ginseng. Biol Pharm Bull 1993;16:1087-90.

48. Mizuno M, Yamada J, Terai $\mathrm{H}$, et al. Differences in immunomodulating effects between wild and cultured Panax ginseng. Biochem Biophys Res Commun 1994 May 16;200:1672-8.

49. Srisurapanon S, Rungroeng K, Apibal S, et al. The effect of standardized ginseng extract on peripheral blood leukocytes and lymphocyte subsets: a preliminary study in young health adults. J Med Assoc Thai 1997;80:S81-S85.

50. Smolina TP, Solov'eva TF, Besednova NN. [Immunotropic activity of panaxans-bioglycans isolated from ginseng]. Antibiot Khimioter 2001;46:19-22.

51. Cho JY, Kim AR, Yoo ES, et al. Ginsenosides from Panax ginseng differentially regulate lymphocyte proliferation. Planta Med 2002; 68:497-500.

52. Sonoda Y, Kasahara T, Mukaida N, et al. Stimulation of interleukin-8 production by acidic polysaccharides from the root of Panax ginseng. Immunopharmacology 1998;38:28794.

53. Chan AS, Yip EC, Yung LY, et al. CKBM stimulates MAPKs but inhibits LPS-induced IFNgamma in lymphocytes. Phytother Res 2006;20:725-31.

54. Predy GN, Goel V, Lovlin R, et al. Efficacy of an extract of North American ginseng containing poly-furanosyl-pyranosyl-saccharides for preventing upper respiratory tract infections: a randomized controlled trial. CMAJ 2005;173:1043-8.

55. McElhaney JE, Gravenstein S, Cole SK, Davidson E, O'neill D, Petitjean S, et al. A placebo-controlled trial of a proprietary extract of North American ginseng (CVTE002) to prevent acute respiratory illness in institutionalized older adults. J Am Geriatr Soc 2004;52:13-9.

56. McElhaney JE, et al. COLD-fX stimulates cell mediated immune response of peripheral leukocytes to influenza virus in National Hockey League players. Manuscript in preparation. 2005.

57. Deng Y, Jing Y, Campbell AE, Gravenstein S. Age-related impaired type $1 \mathrm{~T}$ cell responses to influenza: reduced activation ex vivo, decreased expansion in CTL culture in vitro, and blunted response to influenza vaccination in vivo in the elderly. J Immunol 2004;172:3437-46.

58. Miller SC, Shan JJ. CVT E002, 14 a proprietary extract of North American ginseng (Panax quinquefolium) enhances bone marrow and splenic natural killer (NK) cells and monocytes in leukemic mice, and variably influences other hemopoietic and immune cells. Book of abstracts: The North American Research Conference on Complementary and Integrative Medicine. 5-24-2006. Edmundton, $\mathrm{AB}$, Canada.

59. Predy GN, Goel V, Lovlin R, Basu T. Immune modulating effects of daily supplementation of COLD-fX (a proprietary extract of North Amercian ginseng) in healthy adults. J Clin Biochem Nutr 2006;39:162-7.

60. Wang $M$, Guilbert $\mathrm{LJ}$, Ling $\mathrm{L}$, et al. Immunomodulating activity of CVT-E002, a proprietary extract from North American ginseng (Panax quinquefolium). J Pharm Pharmacol 2001;53:1515-23.

61. Wang M, Guilbert LJ, Li J, et al. A proprietary extract from North American ginseng (Panax quinquefolium) enhances IL-2 and IFNgamma productions in murine spleen cells induced by Con-A. Int Immunopharmacol 2004;4:311-5.

62. Summary of studies with CVT-E002(R) in high perfromance professional athletes assesssing the tolerability and outcomes related to cold and flu-like symptoms. First International Scientific Congress on Nutrition Athletic Performance. 8-8-2001. Edmonton, Alberta.

63. Goel DP, Geiger JD, Shan JJ, et al. Dopingcontrol urinalysis of a ginseng extract, Cold$\mathrm{FX}$, in athletes. Int $\mathrm{J}$ Sport Nutr Exerc Metab 2004;14:473-80.
64. McElhaney JE, Goel V, Toane B, et al. Efficacy of COLD-fX in the prevention of respiratory symptoms in community-dwelling adults: a randomized, double-blinded, placebo controlled trial. J Altern Complement Med 2006;12:153-7.

65. Ulbricht C, Chao W, Costa D, et al. Clinical evidence of herb-drug interactions: a systematic review by the natural standard research collaboration. Curr Drug Metab 2008;9:1063-120.

66. Kiefer D, Pantuso T. Panax ginseng. Am Fam Physician 2003;68:1539-42.

67. Scaglione F, Cattaneo G, Alessandria M, Cogo R. Efficacy and safety of the standardised Ginseng extract G115 for potentiating vaccination against the influenza syndrome and protection against the common cold [corrected]. Drugs Exp Clin Res 1996;22:65-72.

68. Sarkar FH. Current trends in the chemoprevention of cancer. Pharm Res 2010;27:945-9.

69. Amin A, Gali-Muhtasib H, Ocker M, Schneider-Stock R. Overview of Major Classes of Plant-Derived Anticancer Drugs. International Journal of Biomedical Science 2009;5:1-11.

70. Brownstein MJ. A brief history of opiates, opioid peptides, and opioid receptors. Proc Natl Acad Sci USA 1993;90:5391-3.

71. Jack DB. One hundred years of aspirin. Lancet 1997;350:437-9.

72. Gubareva LV, Kaiser L, Hayden FG. Influenza virus neuraminidase inhibitors. Lancet 2000;355:827-35.

73. Hayden FG, Atmar RL, Schilling M, et al. Use of the selective oral neuraminidase inhibitor oseltamivir to prevent influenza. N Engl J Med 1999;341:1336-43.

74. Hayden FG, Treanor JJ, Fritz RS, et al. Use of the oral neuraminidase inhibitor oseltamivir in experimental human influenza: randomized controlled trials for prevention and treatment. JAMA 1999; 282:1240-6.

75. Matheson NJ, Harnden AR, Perera R,et al. Neuraminidase inhibitors for preventing and treating influenza in children. Cochrane Database Syst Rev 2007; CD002744.

76. Nicholson KG, Aoki FY, Osterhaus AD, et al. Efficacy and safety of oseltamivir in treatment of acute influenza: a randomised controlled trial. Neuraminidase Inhibitor Flu Treatment Investigator Group. Lancet 2000;355:1845-50.

77. Treanor JJ, Hayden FG, Vrooman PS, et al. Efficacy and safety of the oral neuraminidase inhibitor oseltamivir in treating acute influenza: a randomized controlled trial. US Oral Neuraminidase Study Group. JAMA 2000;283:1016-24.

78. Avula B, Wang YH, Smillie TJ, Khan IA. Determination of Shikimic Acid in Fruits of Illicium Species and Various Other Plant Samples. Chromatographia 2009;69:307-14. 